\title{
A questão ambiental e o desenvolvimento sustentável: um estudo exploratório com base nos fundamentos das teorias institucional e legitimidade
}

Berenice Beatriz Rossner Wbatuba ${ }^{1}$ Cidônea Machado Deponti Rosane Maria Seibert ${ }^{3}$

\section{Resumo}

O objetivo do estudo foi abordar a questão ambiental e o desenvolvimento sustentável à luz das teorias institucional e legitimidade, utilizando-se da análise empírica em duas empresas da região noroeste do estado do Rio Grande do Sul. A metodologia (VERGARA, 2011) classifica a pesquisa quanto aos fins em um estudo exploratório, descritivo e explicativo, e, quanto aos meios, em bibliográfica e estudo de caso, por meio da aplicação de entrevista semiestruturada aos responsáveis pela gestão ambiental nessas empresas. Os resultados apontam que ambas empresas incorporam a questão ambiental na gestão dos negócios e primam pelo desenvolvimento sustentável de suas atividades, desenvolvendo medidas de prevenção e recuperação ambiental. Embora essas incorporações ocorram mais por exigência legal de mercado ou por gestão estratégica, caracterizando o poder das instituições (tanto por meio de normas de ordem legal, quanto relacionadas às crenças, costumes e jogo de poder implícito nas relações sociais da própria comunidade onde estão inseridas), elas também ocorrem pela necessidade do cumprimento do contrato social existente (legitimidade) entre as empresas e a comunidade. $\mathrm{O}$ trabalho demonstra a importância do estudo das teorias para o conhecimento da evolução humana e análise da questão ambiental e desenvolvimento sustentável nas organizações, porém a discussão não se esgota aqui.

Palavras-chave: Desenvolvimento sustentável. Questão ambiental. Teoria institucional. Teoria da legitimidade. Gestão ambiental.

\footnotetext{
${ }^{1}$ Doutoranda em Desenvolvimento Regional (UNISC). Professora da Universidade Regional do Alto Uruguai e Missões (URI). bwbatuba@santoangelo.uri.br

${ }^{2}$ Doutora em Desenvolvimento Rural (PGDR/UFRGS). Professora do Programa de Pós-Graduação em Desenvolvimento Regional da Universidade de Santa Cruz do Sul (UNISC).cidonea@unisc.br

${ }^{3}$ Doutoranda em Ciências Contábeis (UNISINOS). Professora da Universidade Regional do Alto Uruguai e Missões (URI). rseibert@santoangelo.uri.br
} 


\begin{abstract}
The aim of the study was to address environmental issues and sustainable development in the light of institutional and legitimacy theories, using the empirical analysis in two companies in the Northwest region of the state of Rio Grande do Sul - Brazil. The methodology (VERGARA, 2011), classifies research as its purpose in exploratory, descriptive and explanatory study; and as their means in literature review and case study, through semi-structured interview that was applied to those responsible for environmental management in companies. The results show that both companies incorporate environmental issues management of business and excel in sustainable development of its activities, developing environmental prevention and recovery measures. Although these incorporate occur more due to legal requirements, market or strategic management, featuring the power of the institutions (both by rules and norms legal nature, as related to the beliefs, customs and implicit power play in social relations from the community where organizations are inserted) they also occur by the notion of the need for compliance with existing social contract (legitimacy) between businesses and the community. The study demonstrates the importance of studying the theories to the understanding of human evolution and analysis of environmental issues and sustainable development in organizations, however, the discussion does not end here.
\end{abstract}

Keywords: Sustainable development. Environmental issues. Institutional theory. Legitimacy theory. Environmental management.

\title{
1 Introdução
}

A questão ambiental convoca diversos campos do saber a depor e diz respeito ao modo como a sociedade se relaciona com a natureza (GONÇALVES; DESIDERIOI; GUTIERREZ, 2006). Atualmente, a preocupação com o dano ambiental ultrapassa as fronteiras de um Estado que antes agia isoladamente, passando a ser uma preocupação em nível global (BRAGA, 2009).

Não menos relevante, o tema desenvolvimento também tem sido a questão central para muitos teóricos ao longo dos tempos e, ainda nos dias de hoje, faz-se fortemente presente no âmbito das mais variadas disciplinas do saber.

De forma sintetizada, pode-se dizer que as teorias econômicas foram utilizadas como fundamentos da teoria sobre desenvolvimento. O significado do termo "desenvolvimento" em sua trajetória histórica foi frequentemente associado ao sinônimo de "progresso", no período mais especificamente compreendido entre 1880 e 1920, e de "crescimento econômico do PIB-Produto Interno Bruto", demarcado pelos os anos 1940 a 1970. O longo período de expansão do pós-guerra, (1945 a 1973) teve como base um conjunto de práticas de controle do trabalho, tecnologias, hábitos de consumo e configurações de poder político-econômico, que pode ser chamado de regime de acumulação fordista-keynesiano, altamente entrópico, com uma (Divisão Internacional do Trabalho (DIT) clássica, que relacionava o conceito de desenvolvimento à industrializa- 
ção e urbanização.

A partir da década de 1970, e mais precisamente a contar dos anos 1980, o tema desenvolvimento começa a experimentar significados de ordem mais qualitativa, tais como a preocupação com a sustentabilidade do meio ambiente, as liberdades individuais, a eliminação da pobreza, a inclusão social, o fortalecimento de regiões, entre outros. Esse período foi denominando de regime de acumulação flexível ou pós-modernidade/pós-fordismo (BENKO, 1999).

A partir deste contexto, enfatiza-se a necessidade de adaptação por parte das organizações que conduzam a novos caminhos para sua expansão ou tão somente sua própria manutenção no mercado. Há urgência de mudança de paradigma, de visão empresarial, de objetivos, valores e estratégias que conduzam à nova realidade, corretamente ecológica e socialmente justa, e com uma adequada gestão ambiental, capaz de minimizar a influência da incerteza na tomada de decisão e de provocar mudanças nos processos operacionais, que as organizações estejam engajadas efetivamente na questão ambiental (KRAEMER, 2005) e, assim sendo, sejam percebidas como legítimas na sociedade (SHOCKER; SETHI, 1973; O'DONOVAN 2002), confirmando sobretudo a abordagem da teoria institucional em todo esse processo (VEBLEN,1983; NORTH, 1990; SELZNICK, 1996).

Em razão do exposto, o estudo procurou responder à seguinte questão: Como se dá a abordagem da questão ambiental e do desenvolvimento sustentável pelas empresas em estudo com base nos fundamentos das teorias institucional e legitimidade?

Nesse sentido, o objetivo deste estudo foi abordar a questão ambiental e o desenvolvimento sustentável à luz dos fundamentos das teorias institucional e legitimidade, utilizando-se da análise empírica em duas empresas de grande porte da região Noroeste do Rio Grande do Sul.

$\mathrm{O}$ artigo segue pela fundamentação teórica, parte em que apresenta conceitos sobre o desenvolvimento sustentável na perspectiva histórica; expõe a evolução da teoria institucional e destaca os conceitos que dão suporte à legitimidade das organizações. Após, apresenta-se a metodologia utilizada; os resultados do estudo empírico com as inferências teóricas cabíveis e, por fim, as referências utilizadas no estudo.

\section{Desenvolvimento sustentável na perspectiva histórica}

Apesar do apelo pretensamente universal, não há muito consenso sobre os valores que se abrigam por trás da ideia de desenvolvimento sustentável. Até meados do século passado, a preocupação com a questão ambiental não passava de um luxo elitista e uma excentricidade científica em que poucos consideravam os problemas ambientais como objetos importantes de estudo, e pequena parcela de pessoas comuns sentia significativamente os efeitos da intensificação das atividades econômicas (SOUZA, 2000).

O grau de consciência e a natureza dos problemas ambientais identificados como fonte de preocupação pública, privada e de movimentos ambientalistas pode ser disposto em quatro fases: fase seminal; fase de massificação; fase de globalização l e fase de globalização II. 
a) Fase seminal: ênfase na conservação dos recursos e natureza existencial e estética do meio ambiente. A maior parte da população, estava preocupada em desfrutar as promessas de consumo que a sociedade "fordista" proporcionava, sem vinculação direta com a degradação ambiental, a saúde humana e o bem-estar social. Alguns dos problemas ambientais identificados pelos ativistas referiam-se apenas à extinção de espécies, modificação de paisagens, desmatamentos e deterioração de ambientes naturais como possível destinação ao lazer (daí as primeiras políticas públicas no Brasil tratarem essencialmente do disciplinamento do uso dos recursos naturais, como Código Florestal e das Águas (1934), Código da Pesca (1938), Mineração (1940) e Estatuto da Terra, em 1964 (SOUZA 2000);

b) Fase de massificação: a degradação ambiental começa a afetar o bem-estar das pessoas, que deriva de todos os fatores da fase anterior e são inerentes ao modelo de crescimento econômico hegemônico; deixando, porém, de ter uma conotação existencial, ética e intangível e passando a fazer parte do mundo concreto das pessoas, sendo percebida com maior profundidade com relação à poluição do ar, da água, do solo e do espaço urbano (causado por resíduos industriais, agrícolas, lixo e esgoto doméstico), embora ainda de curto prazo e delimitação local (SOUZA, 2000);

c) Fase de globalização I: o problema ambiental como limite ao crescimento. A década de 1970 representa um marco na forma do mundo compreender a relação com o meio ambiente, emergindo como fator de restrição ao modelo de crescimento econômico que se tinha experimentado com tanto sucesso após a II Guerra Mundial (importou-se em um crescimento de produção e consumo sem precedente no século XX) e que estava apresentando o efeito colateral da degradação dos recursos naturais, a ponto de se tornar insustentável. Nesse ponto, os problemas transcendem as dimensões locais e ganham dimensões internacionais e implicações sobre o futuro do modelo de desenvolvimento econômico baseado na produção e no consumo intensivo (SOUZA, 2000). Tem-se o início da construção da ideia de que "é melhor prevenir do que remediar" e de que o tratamento desses problemas deveria fazer parte do planejamento do próprio desenvolvimento. Manifestam-se aí os primeiros eventos que marcam a década de 1970: a Conferência de Estocolmo (1972); os estudos elaborados pelo Clube de Roma (entre 1972 e 1976) e o relatório elaborado pelo Conselho Ambiental Americano em 1980 - Global Report (SOUZA, 2000);

d) Fase de globalização II: o problema ambiental como risco à humanidade de degradação dos recursos ambientais, que passam a ser vistos sob a ótica dos efeitos sobre o equilíbrio dos ecossistemas e sobre a sustentabilidade da própria vida no planeta. Então, a partir do início dos anos 1980, buscam-se alternativas de conciliação entre o desenvolvimento e a preservação ambiental, 
por meio de duas abordagens: o desenvolvimento sustentável (referindo-se à concepção presente no Relatório Brundtland - que corresponde ao modelo hegemônico, também chamado de desenvolvimento sustentável de mercado) em contraposição ao ecodesenvolvimento - referindo-se à concepção de desenvolvimento sustentável alternativo (SOUZA, 2000). Assim, as características gerais desta última fase podem ser resumidas em 1) abordagem da prevenção; 2) desvinculação da ideia de incompatibilidade entre crescimento e preservação ambiental, com a incorporação da ideia de que o crescimento, nos países pobres, é fundamental para a preservação ambiental (contrariando a posição da década de 1970); 3) surgimento do conceito de "desenvolvimento sustentável", representando exatamente o modelo de compatibilidade entre crescimento econômico e preservação; 4) mudança do significado de "problema ambiental", passando de perigo de esgotamento de recursos naturais para uma abordagem de risco ecológico sistêmico.

\section{Teoria Institucional}

A Teoria Institucional, para chegar ao que se entende dela nos dias de hoje, vem evoluindo ao longo do tempo e, segundo Veblen (1983), ela passou por vários estágios antes de ser denominada como tal, o que pode ser enquadrado como o velho e o novo institucionalismo. Ao longo de pesquisas, constata-se que ela é uma alternativa à Teoria da Racionalidade (Clássica) e à Teoria Neoclássica e deriva de correntes sociológicas e econômicas. Destacam-se como os principais antecedentes os autores: William Stanley Jevons (1835 a 1882); Leon Walras (1834 a 1910); Karl Marx (1818 a 1883); Émile Durkheim (1858 a 1917) e Max Weber (1864 a 1920). Jevons e Walras foram autores que discutiram a teoria neoclássica; Marx e Weber foram os autores da teoria das classes sociais, e Durkheim tratava da coesão social.

O velho institucionalismo inicia considerando que a incerteza move o mundo e que as instituições o organizam, criticando fortemente a teoria racional, na qual o principal objeto de análise eram as organizações. Foca-se nos processos dinâmicos e na evolução cultural, negando-se a ser uma teoria econômica da eficiência estática e do equilíbrio de mercado, contrapondo-se ao que dizia a teoria racional.

Desenvolve uma análise econômica baseada no estudo das estruturas, das regras e do comportamento das instituições. Essas instituições econômicas observadas eram, monopólios, o Estado e seus organismos, o crédito, as empresas, os sindicatos, as relações entre empresas e empregados, as leis sociais, o sistema previdenciário e os padrões de distribuição de renda (VEBLEN, 1983).

Os institucionalistas entraram em aberta polêmica com os economistas ortodoxos, criticando-os por distorcerem a realidade pelo uso de modelos puramente teóricos e matemáticos, não levando em conta o ambiente institucional que envolve a economia. Os institucionalistas consideram a influência, a coalizão e os valores competitivos como aspectos centrais, com ênfase na estrutura informal e de poder de organizações indivi- 
duais (ZUCKER, 1987). Para os institucionalistas, não é a racionalidade, mas os instintos e os costumes, que movem o comportamento econômico, ou seja, não é a competição pelo mercado, mas por riqueza e poder.

Já para o novo institucionalismo, o foco da interpretação institucional passou a ser a observação das conexões entre os custos de transação e a teoria das organizações, analisando as relações econômicas que ocorrem nas organizações, ou seja, o objeto de análise é ampliado e abrange as relações organização - ambiente. Ele também é interorganizacional e societal e envolve as relações econômicas que ocorrem no universo organizacional, destacando que a atenção está dedicada às instituições econômicas no ambiente das empresas (WILLIAMSON, 1996).

A maneira como se posiciona em relação à intervenção governamental na economia é, portanto, o principal fator de distinção entre o velho institucionalismo e o novo. Enquanto a primeira tem uma visão favorável, a segunda, por princípio, tem uma visão contrária à intervenção governamental e aponta dois aspectos que devem ser levados em consideração ao se analisar o desempenho econômico de uma nação: as regras do jogo (correspondem às instituições, tais como todos os valores, convicções, crenças e regras de conduta aceitas consensualmente por uma sociedade) e a capacidade dos jogadores (corresponde à capacidade de desempenho dos agentes econômicos na competição do mercado).

North (1990), por sua vez, um dos principais autores institucionalistas, ao voltar atrás no radicalismo da incerteza e aceitar a racionalidade, insere a variável da temporalidade para tirar a noção de mundo estático e sem fricções. A temporalidade justifica as mudanças que ocorrem nas instituições e, se não pode explicar todo o resultado econômico das organizações, pode explicar o seu incremento.

Powell e DiMaggio (1990) dizem que o novo institucionalismo, como evolução do velho, tem a influência do construtivismo social. Ele valoriza o cognitivo, enfatiza a legitimidade de conjunto das organizações, ou seja, segue mais a orientação sociológica.

North (1990) afirma que as evoluções institucionais são mais importantes que as inovações tecnológicas para o desenvolvimento econômico. Esse mesmo autor e também Selznick (1996) falam que as incertezas movem o mundo, e que as instituições o organizam. As instituições suprem as falhas de mercado, baixam os custos de transação e tornam eficientes os sistemas econômicos e políticos (NORTH, 1990; SELZNICK, 1996; WILLIAMSON, 1996).

Para contextualizar o institucionalismo e sua evolução histórica, julga-se importante transcrever, a seguir, algumas porções do que estes autores diziam à época dos seus escritos.

Velho Institucionalismo:

a) Thorstein Veblen (1857 - 1929) - EUA - a partir do seu livro "A teoria da classe ociosa", além de falar da evolução das instituições, também propunha a existência de uma motivação humana que encaminhasse o homem para o autoconhecimento e o do seu meio para o progresso social. Rejeitava os postulados e conclusões da teoria econômica convencional, queria uma teoria 
econômica evolutiva, queria construir uma teoria de processos. Considerava fundamentais duas instituições: a propriedade privada e a tecnologia. Acreditava que a economia estava atravessada pela contradição entre o avanço tecnológico e os interesses dos proprietários que buscavam o lucro. Defendia reformas democráticas para distribuição equânime dos bens e da renda. Estava preocupado com custos e benefícios sociais.

b) John R. Commons (1862 - 1945) Ohio (EUA) ressaltava que a Economia Institucional contém uma incerteza na definição do que é uma instituição, às vezes, significa um conjunto de leis e de direitos naturais sem os quais os indivíduos agiriam como animais. Em outras, é algo adicional ou crítico da economia clássica. Às vezes, ainda, é tudo que se refere ao comportamento econômico, ou, às vezes, é tudo que é dinâmico, tudo que é processo, atitude, gestão e controle. Para ele, instituição é tudo isso, além de incorporar a visão comunista, anarquista, sindicalista, fascista, cooperativista e o comportamento econômico (COMMOMNS, 1931). Além desses dois autores, tem-se ainda Wesley C. Mitchel (1874 - 1948) - New York - que foi aluno de Veblen. Inspirado em Darwin e nas teorias evolucionistas, afirmava que o fundamental era captar o movimento e a evolução das instituições.

Novo Institucionalismo: North e Selznick são considerados os precursores, embora outros autores defendem essa categorização:

a) Douglass C. North (1990): introduz o conceito de incerteza e rejeita a "rational choice", sendo este o conceito mais fundamental da sua teoria. "Na presença da incerteza e para superar os custos de transação surgem as instituições". Instituições reduzem incertezas por proverem de uma estrutura a vida diária; propõe uma alternativa à teoria racional para resolver dois principais problemas: a motivação dos agentes e o problema de decifrar o ambiente.

Introduz a ideologia na análise econômica e diz que ideias, dogmas e ideologias influenciam o processo decisório racional. Numa segunda fase, depois de críticas, propõe reelaborar a teoria racional, incorporando a dimensão temporal nas análises do desenvolvimento econômico das sociedades para tirar a concepção de mundo estático e livre de fricções (NORTH, 1990). Para o autor, as instituições são as regras do jogo em uma sociedade, mais formalmente, representam os limites estabelecidos pelo homem, para disciplinar as interações humanas, as quais, em consequência, estruturam os incentivos que atuam nas trocas humanas, sejam elas políticas, sociais ou econômicas.

Como elementos centrais da obra de North (1990) encontram-se:

- O direito de propriedade define as regras do jogo (o que é uma inspiração liberal) e estabelece a matriz institucional.

- Dependência do percurso - path dependence, no qual o diferencial na performance econômica, ao longo do tempo, é fundamentalmente influenciado pelos caminhos percorridos pelas instituições. 
b) Philip Selznick (1996): defende que o institucionalismo teve uma influência enorme na arte de administrar, ainda que tenha falhado em alguns problemas centrais da organização e da governança. Chama o institucionalismo de novo paradigma. O autor afirma que "No fundo, institucionalização é uma ideia neutra, que pode ser definida como a emergência de padrões socialmente integradores, ordeiros e estáveis a partir de atividades instáveis, frouxamente organizadas e estreitas, tecnicamente". Procura demonstrar que as forças ambientais condicionam e institucionalizam a ação organizacional e vêm ligar-se às necessidades de sobrevivência, reconhecimento social e de adaptação aos interesses existentes no ambiente.

c) Powell e DiMaggio (1990): afirmam que o velho institucionalismo estava circunscrito a uma base local. Etnometodologia e construtivismo social são considerados fundadores da perspectiva institucional. Dizem que a visão da realidade é construída e analisam as organizações inseridas num setor, campo ou sociedade.

d) William. R. Scott (1987): nos anos 1940 e 1950, houve a explosão do enfoque orientado para a análise do comportamento do indivíduo. Essa orientação foi responsável pelo enfraquecimento da perspectiva institucional e ressalta aspectos de convergência entre o velho e o novo institucionalismo.

e) Meyer e Rowan (1977): são da vertente sociológica e afirmam que a Teoria Institucional prevê que a estrutura formal e o sistema de gestão podem seguir padrões originários de crenças, valores e ideias compartilhados, às vezes sem vínculo, com resultados obtidos pelas práticas e procedimentos adotados.

f) Geoffrey Hodgson (2006): salienta que, de 1950 a 1970, a corrente principal da economia muda radicalmente para o paradigma neoclássico. Depois disso, o abandono da santíssima trindade da economia (racionalidade, ganância e equilíbrio) gera uma excelente oportunidade para o institucionalismo, porque ele enfatiza a dinâmica, a incerteza e a racionalidade limitada. Ele destaca que as regras da economia mundial abandonam a teoria da interação econômica (década de 1980), por problemas de instabilidade, reforçando a economia institucional, não deixando as conexões, mas sim regrando e limitando a interconectividade.

\section{Teoria da legitimidade}

Todas as organizações objetivam ser admiradas por seus funcionários, parceiros, investidores, clientes, fornecedores, governo e sociedade como um todo. Assim, as organizações buscam ser percebidas pelos seus públicos de interesse como legítimas a fim de seus produtos e serviços serem consumidos (SANTANA, 2012). 
As organizações buscam ter um bom relacionamento com a comunidade em que estão inseridas, pois este relacionamento é validado pela sociedade, que lhe concederá legitimidade para que continue atuando nesta comunidade (SUCHMAN, 1995). Assim, a ideia central da teoria da legitimidade é a de que existe um contrato social implícito ou explícito entre as organizações e a comunidade onde elas estão inseridas, e que, para tal, elas devem agir dentro de limites que geram credibilidade, os quais a sociedade identifica como comportamento social aceitável (SUCHMAN, 1995; O'DONOVAN, 2002).

Em outras palavras, a legitimidade pode ser definida como uma percepção ou suposição generalizada de que as ações de uma entidade são desejáveis e apropriadas dentro de um sistema socialmente construído de normas, crenças e valores sociais (SUCHMAN, 1995). Se ela não cumprir com o contrato social, agindo em dissintonia com os interesses de sua comunidade, pode haver penalidades de natureza econômica, legal ou social (LINDBLOM, 1994).

A legitimidade da organização precisa ser naturalmente conquistada por meio do poder legítimo conferido às organizações pelos seus stakeholders (WEBER, 2005; ELIJIDO-TEM; KLOOT; CLARCKSON, 2010; SANTANA, 2012). A gestão da legitimidade perpassa pela comunicação persuasiva e eficiente (ASHFORTH; GIBBS, 1990) entre as organizações e os seus vários públicos de interesse (DOWLING; PFEFFER, 1975; SUCHMAN, 1995; NEU; WARSAME; PEDWELL, 1998). A gestão da legitimidade pode ser estabelecida por perspectivas diferenciadas: estratégica ou institucional.

A perspectiva estratégica propõe que a legitimidade se configura como um dos elementos de competição e conflito entre as organizações sociais, envolvendo diferentes pontos de vista e sistemas de crenças (ASHFORTH; GIBBS, 1990). Na perspectiva institucional, a legitimidade é retratada como um conjunto de crenças constitutivas (SUCHMAN, 1995), ou seja, as definições culturais determinam como a organização é construída, dirigida, ao mesmo tempo em que é entendida e avaliada (DOWLING; PFEFFER, 1975; ASHFORTH; GIBBS, 1990; SUCHMAN, 1995). A legitimidade institucional se subdivide em três tipos: pragmática, moral e cognitiva (SUCHMAN, 1995; O'DWYER; OWEN; UNERMAN, 2011).

A legitimidade pragmática repousa sobre os interesses de audiências mais imediatas da organização, envolvendo intercâmbios diretos entre organização e público, além de interdependências políticas, econômicas ou sociais mais amplas, em que a ação organizacional afeta o bem-estar do público (DOWLING; PFEFFER, 1975; SUCHMAN, 1995). A legitimidade moral reflete a crença de que a atividade promove efetivamente bem-estar social, conforme definido pelo sistema socialmente construído (SUCHMAN, 1995). Já a legitimidade cognitiva decorre, principalmente, da disponibilidade de modelos culturais, onde as atividades organizacionais devem ser previsíveis e significativas (SUCHMAN, 1995).

A legitimidade que se busca identificar é a baseada na audiência dos interessados, para perceber o alinhamento entre as estratégias que as organizações usam, para ganhar, manter e/ou reparar sua legitimidade, versus o que o público quer ver transparente.

Manter a legitimidade conquistada pela organização é mais fácil do que ganhá-la ou repará-la, em razão desta legitimidade dificilmente ser reavaliada, pois a percepção 
do público tende a ser rotineira, a menos que algum fato grave aconteça para mudar a percepção dos stakeholders (SUCHMAN, 1995), fazendo-a perder legitimidade (O'DONOVAN, 2002).

As estratégias para reparar, ganhar ou manter a legitimidade perpassam pela percepção de mudanças futuras e de reações da sua audiência diante dos novos desafios, buscando proteger as realizações passadas, convertendo a legitimidade percebida eventualmente em contínua, defendendo, reforçando ou aumentando a sua legitimidade (LINDBLOM, 1994; SUCHMAN, 1995).

\section{Gestão socioambiental}

O envolvimento cada vez mais intenso das pessoas e das organizações é notório, no sentido de aumentar os seus índices de satisfação em relação aos cuidados com o meio ambiente. Assim, a gestão ambiental torna-se de grande relevância, tendo o intuito de mobilizar as organizações para se adequarem à promoção de um meio ambiente ecologicamente equilibrado, sendo ela encarada como um assunto estratégico, porque, além de estimular a qualidade ambiental, também possibilita a redução de custos diretos (redução de desperdícios com água, energia e matérias-primas) e indiretos (por exemplo, indenizações por danos ambientais).

A grande preocupação com os recursos naturais como a água, o reflorestamento, a reciclagem, entre outros, vem alavancando cada vez mais a gestão ambiental como ferramenta de controle, pois "[...] se não houvesse pressões das sociedades e medidas governamentais, não se observaria o crescente envolvimento das empresas em matéria ambiental" (BARBIERI, 2007, p. 113).

O compromisso com o ser humano, de acordo com Braga (2009, p. 1), tanto está dentro da empresa, por meio do desenvolvimento profissional dos colaboradores e da melhoria de sua qualidade de vida, como na comunidade, decorrentes dos efeitos provocados pelas suas ações sociais, mudando o comportamento humano dos cidadãos, pois o meio ambiente é um elemento essencial para a vida e, por isso, deve ser tratado como um tema transversal, de responsabilidade social e ambiental nas empresas, porque envolve, além do próprio meio (visão ecológica), todas as realizações deste com o homem, seja por meio do processo de educação ambiental, descartabilidade de recursos, prevenção e recuperação de impactos, ou decorrentes da própria existência humana e suas relações com o meio ambiente (BRAGA 2009, p. 1).

De acordo com o proferido no Relatório de Brutland, de forma resumida, o conceito de desenvolvimento sustentável deve integrar três vetores: ambiental, econômico e social. 
Figura 1 - Triple Botton Line

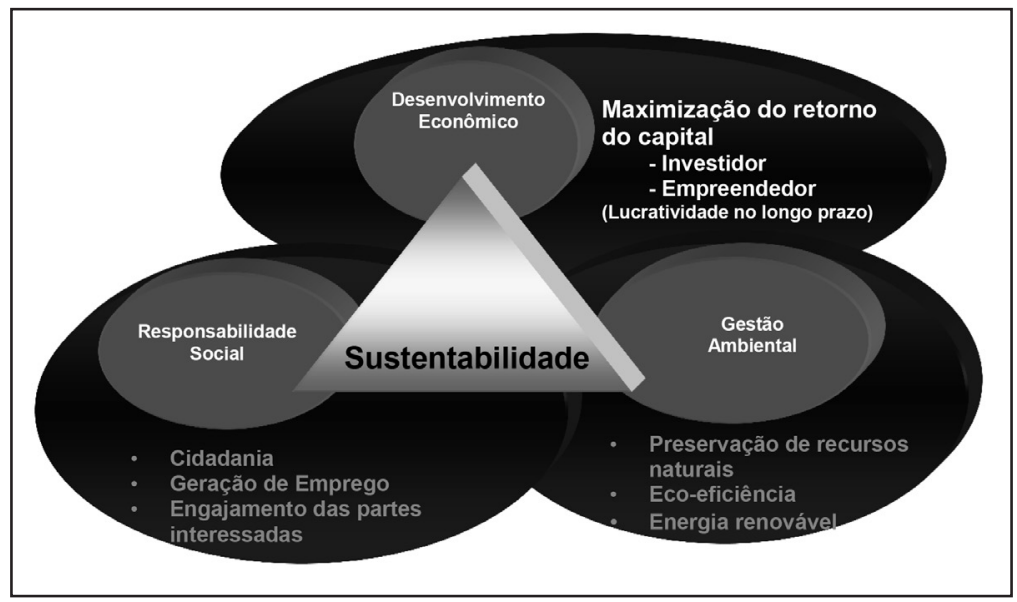

Fonte: adaptada pela Price Waterhouse Coopers (2003).

Meyer (2000) enfoca que, sob esta ótica, o conceito de desenvolvimento sustentável apresenta pontos básicos que devem considerar, de maneira harmônica, o crescimento econômico, uma maior percepção com os impactos sociais decorrentes e o equilíbrio ecológico na utilização dos recursos naturais.

\section{Metodologia}

O estudo seguiu a metodologia proposta pela tipologia de Vergara (2011), que classifica a pesquisa quanto aos fins em a)Exploratória, pois pretendeu atingir uma área na qual há pouco conhecimento acumulado; b) Descritiva, porque descreveu as medidas adotadas e os resultados encontrados pelas empresas em estudo com apreciação dos processos de prevenção e recuperação do meio ambiente, e c)Explicativa, porque explicou como as referidas empresas vêm tratando a questão ambiental e o desenvolvimento sustentável frente aos seus públicos de interesse, a fim de serem percebidas como legítimas pela sociedade, bem como destacou a influência da teoria institucional nesse processo.

Quanto aos meios, a pesquisa caracteriza-se como bibliográfica e estudo de caso, por analisar empiricamente duas empresas da região Noroeste do Rio Grande do Sul.

Os dados e as informações foram coletados através de entrevistas semiestruturadas, aplicadas pelas pesquisadoras aos gestores responsáveis pela gestão ambiental das empresas.

Os dados foram tratados de forma qualitativa, e os resultados obtidos através das entrevistas analisados por meio da análise de conteúdo, com a finalidade de apresentar como as referidas empresas vêm tratando a questão ambiental e o desenvolvimento sustentável frente aos seus públicos de interesse, à luz dos fundamentos das teorias institucional e legitimidade. 


\section{Análise dos resultados}

Apresentam-se, inicialmente, as organizações que são objeto do estudo empírico, seguindo-se a análise dos resultados com base nos dados obtidos por meio da aplicação de entrevista semiestruturada aos gestores responsáveis pela questão ambiental nas duas empresas, a fim de verificar como elas vêm tratando a questão ambiental e o desenvolvimento sustentável frente aos seus públicos de interesse, sob a ótica da teoria da legitimidade (LINDBLOM, 1994; SHOCKER; SETHI, 1973; SUCHMAN, 1995) e da teoria institucional (VEBLEN, 1983; SCOTT, 1987; NORTH, 1990; SELZNICK, 1996; WILLIAMSON, 1996).

A pesquisa foi realizada em duas empresas localizadas na região Noroeste do Rio Grande do Sul, e, por questões éticas, elas serão denominadas de empresa " $X$ " e empresa " $Y$ ".

EMPRESA X - é uma sociedade anônima que atua na área de alimentos e bebidas, cuja forma de controle de capital também é essencialmente nacional e de caráter privado.

EMPRESA Y - é uma sociedade limitada, especializada na fundição de ferro (cimento e nodular) e usinagem, com forte e atuante mercado tanto em nível regional quanto nacional, com controle de capital nacional e de caráter privado.

Para melhor compreensão e análise, os resultados do estudo serão apresentados de acordo com o foco das questões aplicadas aos sujeitos da pesquisa, contendo as respostas das empresas que constituíram a amostragem deste estudo. Dessa forma, os resultados serão subdivididos em três itens, a saber: ações relacionadas à gestão ambiental; aspectos legais e ações ambientais desenvolvidas para a comunidade.

\section{Ações relacionadas à gestão ambiental}

O foco principal dessas questões foi a gestão ambiental, no que se refere às medidas relacionadas à conservação ambiental, à política ambiental e à gestão de metas ambientais, bem como o desenvolvimento ou não de treinamentos voltados à conscientização e alcance de metas ambientais.

Diante dos questionamentos aplicados, ambas as empresas afirmaram possuir algumas medidas relacionadas à gestão ambiental, e que tais medidas são adotadas devido à exigência legal e de gestão estratégica, o que corrobora com a abordagem institucionalista (as instituições são as regras do jogo - North (1990), salientando-se que a empresa " $Y$ " ainda relacionou a existência de medidas provocadas pela exigência (necessidade) do mercado consumidor e justificou que, com o crescente aumento da concorrência entre as empresas, torna-se cada vez mais essencial que os gestores desenvolvam medidas estratégicas para conquistar novos clientes, e uma delas está relacionada com a questão ambiental, que, por se tratar de um tema novo, torna-se um diferencial agregador de valor para as empresas. Destarte, a empresa " $Y$ " trata os resíduos produzidos nos processos produtivos, seguindo rigorosamente as normas nacional e internacional de controle. Um exemplo citado pelo gestor é a areia descartada na fundição, considerado um dos maiores problemas na geração de resíduos sólidos, onde vem desenvolvendo 
projetos alternativos para a reutilização dessa areia como matéria-prima para a construção de pavimentos (blocos) de concreto que são comercializados.

Com relação às políticas ambientais, ambas possuem políticas formais, expondo e declarando os seus princípios e intenções em relação ao seu desempenho ambiental e às metas as quais desejam atingir em relação à preservação ambiental. As empresas informaram ainda que possuem programas de treinamento para a conscientização e o alcance das metas ambientais, tais como palestras relacionadas à questão ambiental, abordando a correta utilização dos recursos naturais, assim como treinamentos realizados para a coleta seletiva do lixo e reciclagem, oferecidos especificamente para os funcionários, pois entendem que eles devem ter consciência dos danos que alguns processos de fabricação dos produtos podem causar, prejudicando em grande escala o meio ambiente. Esse posicionamento institucional está coerente com o que preconiza a teoria da legitimidade, pois as organizações precisam agir de acordo com os interesses dos seus públicos e também beneficiar a comunidade com retornos sociais de melhoria (LINDBLOM, 1994; O'DONOVAN, 2002; SHOCKER; SETHI, 1973; SUCHMAN, 1995).

As organizações afirmam fazer tanto o tratamento primário quanto secundário de seus resíduos decorrentes de processos produtivos, sejam eles resíduos líquidos, sólidos ou gasosos, sendo que a empresa " $Y$ " utiliza-se da classificação de seus resíduos e, quando tecnicamente viáveis, esses resíduos são transformados em produtos comercializáveis, ou matérias-primas a serem usadas como insumos em outros processos de produção, enquanto que os resíduos não recicláveis são corretamente destinados, ou tratados, conforme exigências legais. A empresa " $X$ " possui soluções para o tratamento de efluentes e sistemas de produção que preservam os recursos naturais. Tanto o plástico como o vidro que a empresa utiliza para acondicionar seus produtos são recicláveis, além disso, promove projetos direcionados para redução da geração de seus resíduos, como, por exemplo, a iniciativa de diminuição da gramatura de embalagens pet e das tampas de garrafas, representando uma significativa diminuição do uso do plástico.

\section{Aspectos legais}

Neste item, o foco das questões aplicadas foi verificar as ações das empresas em relação ao aspecto legal da questão ambiental. Nesse sentido, constatou-se que ambas as empresas possuem certificação ambiental e geralmente referem-se à Série ISO 14000, a qual padroniza os processos de fabricação. A empresa " $Y$ " informou que possui certificação de 5 a 10 anos e que os resultados alcançados, após a certificação da Série ISO 14000 , foram a melhoria no desempenho operacional, reduzindo o consumo de água e de energia, e também um gerenciamento de resíduos, além de uma melhoria nos negócios. Já a empresa " $X$ " possui certificação de 2 a 5 anos, e o principal resultado alcançado foi na área organizacional, o que engloba a estruturação de uma política ambiental interna: planejamento, prevenção, comunicação, conscientização e comprometimento, além de uma melhoria também no desempenho operacional.

O estudo buscou investigar a responsabilidade na gestão ambiental e verificou que, nas duas empresas, essa responsabilidade é formal e declarada, sendo que, na empresa "Y", a área corporativa que responde pela gestão ambiental é a de Recursos 
Humanos; já na empresa " $X$ ", essa responsabilidade se dá através de um Sistema de Gestão Integrada, porém todos os gestores e funcionários devem possuir conhecimento sobre o tema, para que, assim, todos colaborem com o desenvolvimento sustentável em cada uma de suas áreas.

Averiguou-se, também, que os impactos ambientais provocados pelas atividades são conhecidos pela alta administração, de maneira documentada em ambas as empresas, o que é muito importante, pois os gestores devem ter a consciência dos efeitos que suas atividades operacionais causam ao meio ambiente. Assim, quando reconhecidos os impactos ambientais, estes se referem a todos os processos, no caso da empresa " $Y$ ", enquanto que para a empresa " $\mathrm{X}$ " tais impactos se referem apenas aos processos produtivos.

\section{Ações ambientais desenvolvidas para a comunidade}

Neste ponto, buscou-se identificar se as empresas promovem ações ambientais para a comunidade em que estão inseridas e de que forma o fazem. A empresa " $Y$ " disse promover poucos projetos nesse sentido, porém vê urgência por parte da comunidade para essa demanda. Já a Empresa " $X$ " promove ações ambientais e não poupa investimentos para levar qualidade de vida à população. Promove projetos que visam habilitar a comunidade e desenvolver práticas ambientalmente sustentáveis. São iniciativas que visam à capacitação de jovens, empreendedores, clientes e funcionários, além de proporcionar diversas outras oportunidades. A empresa participa, desde o ano de 2003, do "Projeto Pescar", por meio do qual jovens são capacitados em vendas e atendimento ao cliente, além de formação voltada à cidadania, com conteúdo sobre saúde, meio-ambiente e ecologia, comunicação, autoestima, ética, criatividade, estrutura e planejamento familiar, ambiente de trabalho, direitos e deveres. Essas atitudes confirmam a preocupação das organizações com a sua comunidade, demonstrando que entendem que precisam manter a legitimidade porque dela depende a sua perenidade.

\section{Considerações finais}

Este trabalho foi desenvolvido com o intuito de analisar como duas empresas de grande porte da região Noroeste do Rio Grande do Sul estão abordando a questão ambiental e o desenvolvimento sustentável, demonstrando que atendem às regras do jogo, sejam elas formais ou informais, conforme preconiza a teoria institucional, e que são cumpridoras do contrato social, conforme preconiza a teoria da legitimidade.

$\mathrm{Na}$ intenção de atingir o objetivo proposto, foi realizada uma breve revisão histórica acerca do desenvolvimento sustentável, da Teoria Institucional (VEBLEN, 1983; SCOTT, 1987; NORTH, 1990; SELZNICK, 1996; WILLIAMSON, 1996), da Teoria da Legitimidade (LINDBLOM, 1994; O’DONOVAN, 2002; SHOCKER; SETHI, 1973; SUCHMAN, 1995), e da Gestão Ambiental.

Para o desenvolvimento do estudo empírico, foram feitas entrevistas com os gestores responsáveis pela questão ambiental nas duas empresas. Com base nos resulta- 
dos obtidos na análise do instrumento de pesquisa, pode-se perceber que as empresas questionadas desenvolvem medidas relacionadas à questão ambiental motivadas por exigência legal, gestão estratégica e por exigências do mercado consumidor, o que confirma a fala de Barbieri (2007, p. 113), “[...] se não houvesse pressões da sociedade e medidas governamentais, não se observaria o crescente envolvimento das empresas em matéria ambiental".

As empresas possuem políticas ambientais definidas, com clara gestão de metas, utilizando-se de treinamentos internos para seus funcionários, com objetivos de atingir as metas ambientais traçadas. Ambas as empresas possuem certificação da Série ISO 14000 e demonstraram que obtiveram resultados positivos depois desta certificação, melhorando o desempenho operacional e aumentando a rentabilidade de seus negócios.

De igual forma, ambas as empresas trabalham para a redução dos impactos ambientais causados pelos seus processos produtivos, possuindo meios para o tratamento de seus resíduos e até mesmo, quando tecnicamente possível, transformando-os em produtos comercializáveis para a geração de receita ambiental, ou reciclando materiais que, se jogados no ambiente sem a correta destinação e tratamento, causariam danos ao meio ambiente. Porém, observa-se que, apesar das empresas desenvolverem ações sustentáveis destinadas à redução, minimização ou recuperação dos impactos causados pelos resíduos de seus processos produtivos, estas ações são resultado das instituições, mais formalmente, representam os limites estabelecidos pelo homem para disciplinar as interações humanas, que, em consequência, estruturam os incentivos que atuam nas trocas humanas, sejam elas políticas, sociais ou econômicas (NORTH, 1990).

A incerteza presente no dia a dia das organizações é fato e tem influência na tomada de decisões, assim como nos seus resultados, ficando claro que as instituições têm papel de regular, ou de organizar as relações nos ambientes social, econômico e político até hoje. As instituições são elementos determinantes para o entendimento da realidade organizacional, interorganizacional e societal, como preconiza o novo institucionalismo.

Realizar uma análise baseada na abordagem institucional e no jogo de poder implícito é tentar descobrir que elementos na sociedade detêm mais poder e influência neste momento, e que grupo ou grupos de interesse se beneficiaram mais com essas circunstâncias. Na abordagem institucional, a reflexão sobre as relações entre as organizações e seus ambientes deixa de lado as influências do poder nas demandas do ambiente (seja em produtos ou processos), dando maior prioridade ao ambiente em sua função indutora de "material cultural" para a gestão das organizações. Para essa corrente analítica, a noção-chave é a legitimidade. Os ambientes criam novos elementos organizacionais, transformando-os em necessidades das organizações, considerando-as, posteriormente, mais legitimadas que as outras (MEYER; ROWAN, 1977).

Nesse sentido, a necessidade de fornecer informações cada vez mais detalhadas, precisas e adequadas, tanto para auxiliar o gestor na tomada de decisão quanto para os investidores, sócios e, principalmente, consumidores, é cada vez mais presente e de fundamental relevância para manter e ampliar a legitimidade conquistada por essas empresas. Por isso, devem se esforçar para demonstrar coerência entre a sua dinâmica funcional e os valores culturais daquela comunidade, por meio de uma comunicação persuasiva e eficiente (SUCHMAN, 1995). 
A teoria institucional, ao reacender as relações das tradições sociológicas - Weber e Durkheim - a partir da retomada de elementos esquecidos, como legitimidade, revigora o poder explicativo da teoria organizacional. As transformações do mundo atual, caracterizadas por fenômenos como as fusões, aquisições e expansão da ação de grandes corporações em países em desenvolvimento; revoluções tecnológicas e renovação das práticas de gestão não podem ser explicadas a partir de orientações puramente racionalistas, negligenciando as dimensões socioculturais. Daí a contribuição da teoria institucional, que recoloca no espaço organizacional diferentes racionalidades que vão além da racionalidade limitada e absoluta das teorias advindas da economia clássica.

Da mesma forma que as organizações estão desenvolvendo estratégias globalizadas, os estados e instituições formadores de agentes para atuarem nesses ambientes também vêm atuando cada vez mais interligados e compartilhando, de forma mais intensa, valores sobre questões crucias na estruturação das atividades de produção, lazer, conhecimento. Assim, os valores, crenças, costumes, entre outros, são compartilhados no ambiente de análise das organizações, eliminando o espaço para explicações não científicas, onde as abordagens tradicionais não conseguiam dar resposta.

No que se refere aos instrumentos ambientais utilizados pelas empresas analisadas, conclui-se que elas ainda se encontram numa linha "conservadora" de desenvolvimento sustentável, preconizada pelo mainstream, necessitando aprimorar não só os instrumentos e as práticas relacionadas à questão ambiental como também a formação do pensamento coletivo de sensibilização e conscientização acerca das questões ambientais, para afirmar constantemente sua legitimidade perante a sociedade.

Por fim, este trabalho, apesar de suas limitações, serviu para demonstrar a importância do estudo das teorias, não só para o conhecimento da evolução humana como também para a análise da questão ambiental e do desenvolvimento sustentável nas organizações, ainda que, certamente, essa discussão não se esgote nestas poucas páginas.

\section{Referências}

ASHFORTH, B. E.; GIBBS, B. W. The double-edge of organizational legitimation. Organization Science, v. 1, n. 2, p. 177-194, 1990.

BARBIERI, J. C. Gestão Ambiental Empresarial: conceitos, modelos e instrumentos. São Paulo: Saraiva, 2007.

BENKO, Georges. A Ciência Regional. Oeiras: Celta, 1999.

BRAGA, C. Contabilidade Ambiental: Ferramenta para a Gestão da Sustentabilidade. São Paulo: Atlas, 2009.

COMMONS, John R. Institutional Economics. American Economic Review, Pittsburgh, 1931, v. 21.

COOPERS, P. W. Integral Business: integrando sustentabilidade e estratégia de negócios. São Paulo: Atlas, 2003. 
DOWLING, J.; PFEFFER, J. Organizational legitimacy: Social values and organizational behavior. Pacific Sociological Review, 1975.

ELIJIDO-TEN, E.; KLOOT, L.; CLARCKSON, P. Extending the application of stakeholder influence strategies to environmental disclosures: An exploratory study from a developing country. Accounting, Audititng \& Accountability Journal, 2010.

GONÇALVES, A.; DESIDERIOI, A.; GUTTIERREZ, G. L. A Responsabilidade Social das Empresas. ORG \& DEMO, v. 7, n. 1-2, jan./jun. - jul./dez. 2006.

HODGSON, Geofrey M. What are institutions? Journal of Economic Issues. v. XL, n. 1, 2006.

KRAEMER, M. P. Responsabilidade social uma alavanca para sustentabilidade. 2005. Disponível em: <http://www.gestiopoli.com/canales5/fin/resocial.htm. Acesso em: 5 out. 2012.

LINDBLOM, C. The implications of organizational legitimacy for corporate social performace and disclosure. Critical Perspectives on Accounting Conference, 1994.

MEYER, M. Gestão ambiental no setor mineral: um estudo de caso. Dissertação (Mestrado em Engenharia da Produção) - Universidade Federal de Santa Catarina, Florianópolis, 2000.

MEYER, J. W.; ROWAN, B. Institutionalized organizations: formal structure as myth and ceremony. American Journal of Sociology, v. 83, p. 340-363. 1977.

NEU, D.; WARSAME, H.; PEDWELL, K. Managing public impressions: Environmental disclosures in Annual Reports. Accounting, Organizations and Society, p. 265-282, 1998.

NORTH, Douglass C. Institutions, institutional change and economic performance. Cambridge: Cambridge University, 1990.

O'DONOVAN, G. Environmental disclosures in the annual report: Extending the applicability and predictive power of legitimacy theory. Accounting, auditing and accountability Journal, p. 344-371. 2002.

O'DWYER, B.; OWEN, D.; UNERMAN, J. Seeking legitimacy for new assurance forms: The case of assurance on sustainability reporting. Accounting, Organizations and Society, p. 31-52. 2011.

POWELL, W. W.; DIMAGGIO P. J. The new institutionalism in organizational analysis. Chicago: University of Chicago, 1990.

SANTANA, A. Three Elements of Stakeholder Legitimacy. Journal of Business Ethics, 2012.

SCOTT, W. R. The adolescence of institutional theory. Administrative Science Quarterly, v. 32, p. 493-511. 1987.

SELZNICK, P. Institucionalism “Old" and "New". Administrative Science Quarterly. v. 41, n. 2, p. 270-277, 1996. 
SHOCHER, A.; PRAKASH SETHI, S. An approach to incorporating societal preferences in developing corporate action strategies. California Management Review, p. 97-105. 1973.

SOUZA, Renato Santos de. Entendendo a questão ambiental: temas de economia, política e gestão do meio ambiente. Santa Cruz do Sul: EDUNISC, 2000.

SUCHMAN, M. Managing Legitimacy: Strategic and Institutional Approaches. Academy of Management Review, p. 571-610. 1995.

VEBLEN, Thorstein. A teoria da classe ociosa. São Paulo: Abril Cultural, 1983.

VERGARA, S. C. Projetos e Relatórios em Administração. São Paulo: Atlas, 2011.

WEBER, M. Três tipos puros de poder legítimo. In: A. Morão. Três tipos de poder e outros escritos. Lisboa: Tribuna da História, 2005. p. 1-16.

WILLIAMSON, Oliver E. La naturaliza de la empresa. Mexico: Fondo de Cultura Economica, 1996.

ZUCKER, L. G. Institutional theories of organization. Annual Review of Sociolog, v. 13, p. 443-464. 1987. 